\title{
Dismantling Photographs and Videos in Geography Classes: Notes on High School Methodologies
}

\author{
Sara Heline Rodrigues de Brito Silva \\ Breno de Abreu Lopes \\ Nilson Almino de Freitas \\ Luiz Antonio Araújo Gonçalves
}

Acaraú Valley State University

Brazil

\begin{abstract}
The manuscript presents some notes and results of the pedagogical intervention carried out at José Cláudio de Araújo High School in Mucambo, Ceará. The activities included sophomore students through the project called Dismantling Photographs and Videos in the Geography Classes. The motivation for creating the project was the interest in methodological innovation with the use of teaching practice resources such as photographs, drawings, texts, and videos for a shared construction of a contextualized knowledge. Dismantling is here a method of reading, interpretation, and use of information support, either text or image. In this perspective, dismantling is also useful in Geography classes, mainly in the analysis of photographs, drawings, and texts contained in schoolbooks, as well as in complementary videos. It promotes the development of the students' analytical, critical, and creative capacity, overcoming some viewpoints concerning textbooks, especially the one that places its contents as incontestable. The proposed activity turned students into protagonists in the production of knowledge, giving them conditions to reflect on the contents and stimulating new perceptions from the dismantling and reassembly of contents in a contextualized form. Finally, the intervention proposal helped the students to form other perceptions about the space to which they belong, which is essential in the current social and socioeconomic context.
\end{abstract}

Keywords: Geography Teaching. Dismantling. Photographs. Videos.

\section{Introduction}

This manuscript presents some notes and results on the pedagogical intervention carried out at José Cláudio de Araújo High School in Mucambo, Ceará. The activities included sophomore students through the project called Dismantling Photographs and Videos in the Geography Classes. The principal motivation for planning and carrying out this project in the school was the interest for methodological innovation with the use of teaching practice resources such as photographs, drawings, texts, and videos to build, together with students, a contextualized knowledge of that city.

Dismantling is here a method of reading, interpreting, and using information support, either text or image. The methodology counts on Le Goff's (1990) reflections on the term when it comes to document design. The author reminds the need to be critical concerning written or imagined records. Who creates the document has a viewpoint and, thus, carries in its production convictions and concepts, demonstrating that it is a work based on elements that are not neutral and impartial but loaded with interests, desires, and powers. When someone speaks, writes, or produces an image, the work is an exercise of imposing meaning. It is a concept, not a faithful expression of reality.

In the case of drawing, Azevedo (2016) says that it is an instrument that favors observation, registration and allows the production of an image not necessarily premeditated or exact of what happened, but that the designer wants to show. It is a time-consuming creative composition that tries to recover a moment in space and time so that one can observe again from the designer's technique, style, and form of expression. It allows to include in the landscape elements, shapes, and colors that, many times, a photograph is not able to show or to gather things that are not necessarily together at the moment of the scene. It is a composition of what one wants to show, based on his interests, field of technique, the material used to produce, and the media of the work, which aims to cause an effect on its readers.

Regarding photography and film, Flusser (1985) says that image is not synonymous with these technical means of reproduction of the register made by a machine and an operator. People produce pictures about the world stimulated by their imagination, serving them asa guide for daily life. Photography or film is the technical mean of communicating the image produced, which simultaneously encourages to think about new ones. The problem is that many people see this technical medium as a faithful representation of the world. They unlearned reading technical images as a concept that involves several variables in its composition, precisely because they do not 
understand it this way. It is not possible to see the same thing in terms of color, lighting, depth, and focus of a photo in comparison to what the eyes see. Besides, the world is not the same before the eyes as it is in pictures.

Therefore, photography results from the settings, software, and limits concerning what happen in the environment and context of production. The many variables in the composition of the technical image so that the result causesan effect on the one watching it, especially the one related to the idea that it is an expression of reality.

Do not forget that film is photography. It is an optical effect of movement caused by a sequence of several pictures passing before the eyes for a second. Therefore, photos, drawings, and films are visual expressions that aim to cause an effect on those who see them. It is also a different form of communication from the text. The reading of an image is not from left to right, so it is not linear, which allows multiple interpretations. Because of such a characteristic, the technical image presents itself with the capacity for encouraging imagination, promoting debate and discussion among different opinions. It affects the audience, not only in its feelings. Affection creates a disordering of any fixed cognitive and emotional position over the world. The conditions are not the same, even with the same forces provided by reading the technical image. Not in the sense of identification and empathy, necessarily, since the most common is the promotion of different perceptions, but in the sense of being a force that can promote a review in the individual project of knowledge and rigid practices, allowing improvement.

In the individual relationship as a world, one knows the rules but does not have total control over them. The partial lack of control makes the knowledge about the world become a reason for critical questioning. Thus, affecting favors involvement, shared commitment, the thought that aims at the transformation. It generates sensitivity to recognize the necessary agency in the face of the complexity of the world, even knowing that it lays on the insecurity of its effectiveness. It is experimentation.

Therefore, this movement of affection that characterizes the exercise of disassembly is useful in educational reality, especially when analyzing photographs, drawings, and texts contained in textbooks, as well as complimentary videos used as support. In turn, the production of technical images encourages the imagination and produces newones that will guide individual conduct in the world.

From this perspective, the dismantling is relevant in high school Geography classes. Dismantling school contents consist of the analysis of intentionality that precedes them, going beyond their appearance, favoring the student an environment that affects him, while promoting transformations in his project of knowledge. In turn, it may provoke desires to transform the environment' sreality. The interpretations of information, photographs, texts, and drawings from textbooks adopted by the school, as well as videos related to the contents, were thought and transposed to favor the formation of a posture so that students can act in daily life. A subversion of the original conception of textbook contents, which was discussed and adapted to the world in which students live, creates in them responsibility for the production of contextualized knowledge.

The dismantling includes the identification of points portrayed in textbooks to think about the city in which the students live, to compare their convergences and divergences. They produced new images. With the film or drawing, the method was to see, understand, and dismantle to make. It is a teaching proposal that seeks to awaken in students the ability to understand the intentions perceived according to what is schoolbooks, and also to raise ways for students to find meaning in the contents and to produce images and texts that show a broader concept of where the school is.

The work followed first the methodology of dismantling photographs, texts, drawings, and videos at the abovementioned school during the first semester of 2019. Secondly, there was a pedagogical intervention with the students, which consisted of creating portfolios with photos, comics, mind maps, drawings, videos, and texts produced by the students or originating from personal collections of neighbors. It was an evaluative activity in which some works went to2019 events, such as the own school and Universidade Estadual Vale do Acaraú (Acaraú Valley State University, UVA) science fairs, Ceará Científico (Ceará Scientific). The latter event isfrom the Secretary of Education of the State of Ceará(SEDUC-CE),supported bythe Sixth Regional Coordinator of Education Development(CREDE 6).

Reflecting on this experience, the first part of the article brings some notes on teaching and learning from a perspective of social innovation proposed by the Common National Curricular Base (BNCC) and the relationship with the activity carried out. Next, teachers exposed concerns and the culmination from the project of dismantling textbooks, involving textual production, drawing, photographs, and videos. The next part of the work is the results of the exposition of the portfolios based on the methodology, added to a brief discussion about the repercussions, taken from the visual narratives produced by the students in the portfolio format and testimonials.

\section{Notes on the Brazilian teaching and learning context, youth, and BNCC documents}

Using new methodologies in high school, specifically in the curricular component of Geography, requires teachers an approach that relates the book not only as a resource for understanding contents but also as an instrument that is 
the starting point for other learning possibilities. Thus, it is necessary that teachers offer students new ways of learning and understanding their living space during the study of geographic science, thinking about how they can apply this knowledge in their daily lives through a critical perspective.

Therefore, there is a circumstance that raises variables that must go under discussion in the classroom. The first one comprises the subject in high school, namely young people with different perspectives that reveal the school's need to understand the demands of contemporary social dynamics, marked by the rapid transformations resulting from technological development (BRAZIL, 2019).

The approach of recognizing who is the student in high school is in the National Curricular Guidelines (DCNs), and the BNCC takes up this question on the clarity that must be had on the characterization of these subjects, drawing attention to the heterogeneity of young people in the school context. This approach tends to dispel the idea that youth is a rite of passage, creating social and cultural homogeneity. Young people have a socio-historical-cultural condition in their diversity, and the BNCC guides that they are not only their biological and age condition, homogenizing their conduct and social behavior. Therefore, there are young people with various youth cultures.

With new technology, the formation of symbologies that are their temporal ways related to their use, related to the search and communication via images, videos to emit opinions. The use of symbologies in communication and perception of reality differs when one thinks about the condition of social class, gender, skin color, and place of residence, as the theorists who discuss intersectionality say. Hirata (2014) reminds, quoting Bilge, that intersectionality helps in the understanding of identities concerning social inequalities integrating several variables. Thus, the complexity inherent to the society and the cultural reality of current students must go through consideration within the educational processes and teaching methodologies adopted during the teaching-learning process.

Continuing with the reasoning of considering the languages and diversity of youth, the BNCC reinforces the position that the school can provide an open field for research and intervention on social, productive, environmental, and cultural aspects (BRAZIL, 2019).

In this perspective, dismantling texts, photographs, and videos is a relevant teaching strategy because it takes into consideration the approach between curricular content, intentions portrayed in textbooks, and the experiences of students, who are learning from the dismantling to relate school content to real life.

Despite being at the BNCC, the considerations described regarding youth, their diversity, and the possibilities that the school must offer the student encounter some obstacles to their effectiveness. These difficulties are related to the lack of recognition, on the part of the teachers, that the student can also participate in the teaching-learning process, not only as a passive learner but active in building knowledge and doing, proposing, and creating content. Thus, dismantling the contents from Geography schoolbooks is a methodology that has the possibility of assigning responsibility to the student in his learning, even knowing that only this is not enough.

However, some guidelines in the BNCC bring instructions that point in the opposite direction of the discussion for presenting points demanded by international organizations to establish an economic order focused on the logic of the market. In this way, the school reaffirms itself as the ideological apparatus of the State, also reasserting the vision of young people from their economic usefulness, dual and unequal for the children of the working classes, as elements of the complex mechanism of the market (SANTOS, 2019).

Unlike this teaching model, the dismantling methodology is a way for students to perceive themselves in the educational context and also within the reality of their city, not only as a future worker but as human beings in search of full citizenship. The idea is that they can overcome boundaries between technology and humanity, understanding the impact of their actions on culture and social relations. Thus, this knowledge can give access to the possibility of proposing forms of relationship with the environment they live in, generating a feeling of responsibility for the use of the territory.

It is in this set of possibilities that occur the dismantling in the teaching of Geography because its unfoldings do not depend exclusively on textbooks topics. It is feasible to deal with these and other themes, mixing languages and producing interpretations by the students.

Santos (2019) says that effective learning must start from the awareness of the current time in which one lives, knowing about the world and its functioning, the place, and the relationship with society. From this teaching perspective, there is a significant contribution to an education that makes students recognize themselves and the reality in which they live and participate. Perhaps even more than that, by enabling them to feel responsible for the world in which they live with strength and power to transform it for the better.

\section{Presenting the project Dismantling Photographs and Videos in Geography Classes}


The project had origin in the search for teaching methodologies that would contribute to the process of Geography teaching and learning. In this sense, the authors glimpsed the use of visual arts and textual production in the context of classes, inserting the visualities in the curriculum proposal. The proposal lays on the idea that the teaching and learning process is not only the result of applying a set of techniques or solving problems based on ready-made and finished models.

It is also not based on the idea that the teacher is the owner of knowledge and the student a receptacle of knowledge. It is a methodology that produces the shared research between teacher and student, with a view to reciprocal collaboration in the production of content and its dissemination from the idea of dismantling the technical image to produce new assemblies.

In Geography classes, it is quite common to use videos and images to reinforce the content to support what informs the textbook. Thus, occurred the addition of treatment of geographic topics in high school, starting from the dismantling to the assembly of new content with various languages, relating to the daily lives of students, making comparisons between what the book offers and visual productions of the city. Thus, it is clear the occurrence of natural, socioeconomic, and cultural phenomena in the context in which they live.

The construction of portfolios followed Gama (2001), who defines it as an intentional act of the one who chooses space, time, objects, or people, building a visual and textual narrative on a perception of the territory. Each portfolio proceeded according to the sequence of the Geography pedagogical proposal. In each class, teachers encouraged students to follow these two steps:

$\checkmark \quad \mathbf{1}^{\text {st }}$ step: Choice of three images related to the subjects contemplated in the content, which can be from the textbook.

$\checkmark \quad \mathbf{2}^{\text {nd }}$ step: The images underwent the following questions: who produced them? What elements stand out as revealing the author's intention? What was the perceived purpose? What geographical topicdoes it exemplify? Did it contribute to the understanding of the content?

After a discussion, the team reproduced their interpretations in the portfolios on what they understood from the author's perception. Thus, they did the didactic transposition associating what they understood to what they live daily in their city. To better contextualize their experiences, the students had to discover the reason for the choice of space, object, or person, the relationship between the shown things and what they saw in the textbook,the desires and intentions that guided the production of the portfolio, and the geographic content in the material produced.

Concerning films and videos, teachers asked students about the motivations for the production and what they could compare with their lives, following the contents proposed by the book in alignment with the school's curricular proposal. To the extent that students came up with questions a bout the intention and the kind of video, they linked the text book topicto what they noticed in daily life, producing original videos.

What follows is an outcome obtained with the presentation of the proposal during a sharing moment of school actions, correlating with the perceptions of students regarding the use of the methodology.

\section{Results from the project Dismantling Photographs and Videos in Geography Classes}

The actions taken to dismantle the material presented at the school contributed beyond the goals pointed out about learning. The project caused a significant integration and participation of students in the process of producing knowledge, going beyond what the school offers. Each portfolio in each notebook contained several pages in a logical sequence defined by students and teachers. What follows are commented examples of the work done from portfolio fragments.

In one portfolio, the team produced a mind map with photos, texts, and drawings about the social and economic agents in Mucambo, under the topics about urbanization (Figure 1). The mind map shows the producing agents of urban space (CORRÊA, 1989).The agents in the conflict were about the city and how the intentionalities cause social and economic tensions. The broader tensions and other generic agents are in the mind map. 
Figure 1: Mind map about producing agents of the urban space - Mucambo-CE.

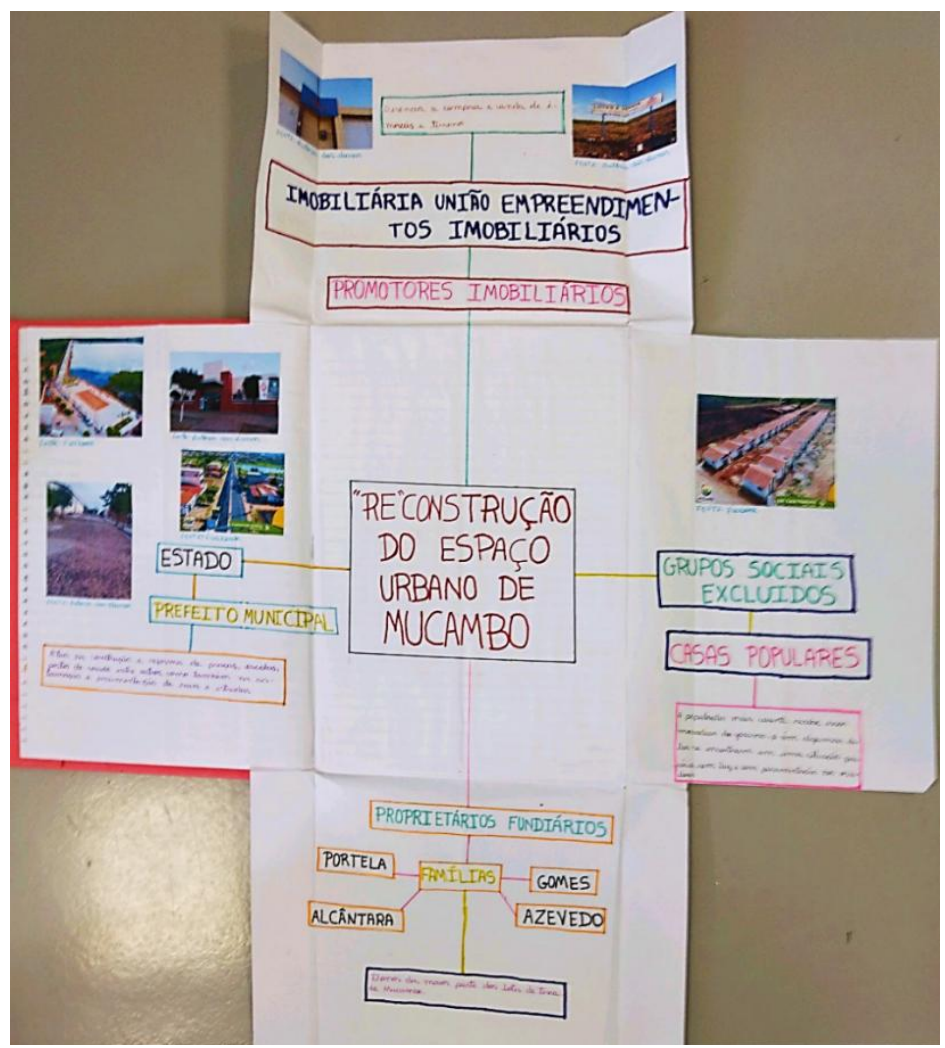

Source: The own authors.

Next, the students pointed out the positive and negative aspects of the presence and performance of the migrant from São Paulo in Mucambo-CE (Figure 2). The occupation of the urban space was once again the reason for this visual reflection. The assembly also had as source the interviews made by the students with the city residents.

Figure 2: Positive and negative aspects of migrants from São Paulo in urban soil production in Mucambo-CE.

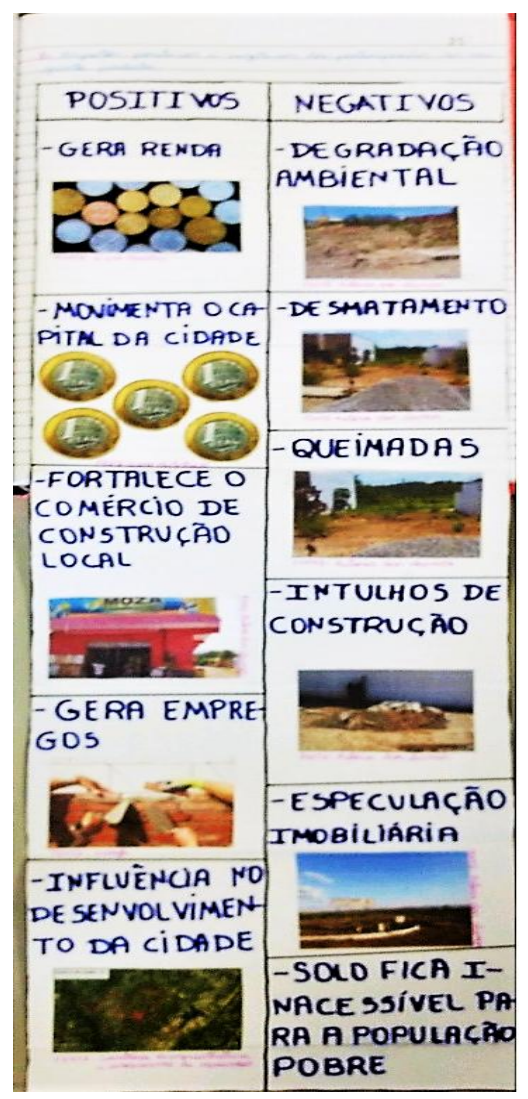

Source: The own authors. 
Figure 3 below shows the design made by a team that worked with proposals for interventions such as infrastructure works on public lands, such as the construction of squares and parks with green areas. Another group, reflecting on the production of urban space, highlighted the participation of public power as one of the agents in the transformation and valorization of the city spaces. In this case, the students identified land and buildings, making proposals for green areas, such as the construction of a culture museum for the city.

At that moment, there was the involvement of different skills when plotted the starting point. Once the student started dismantling and reassembling, the finish line was the recognition of the city's urban space, its positive and negative aspects, making the discussion about his participation and performance as a citizen clearer.

\section{Figure 3: Drawing as a proposal for building squares with green area.}

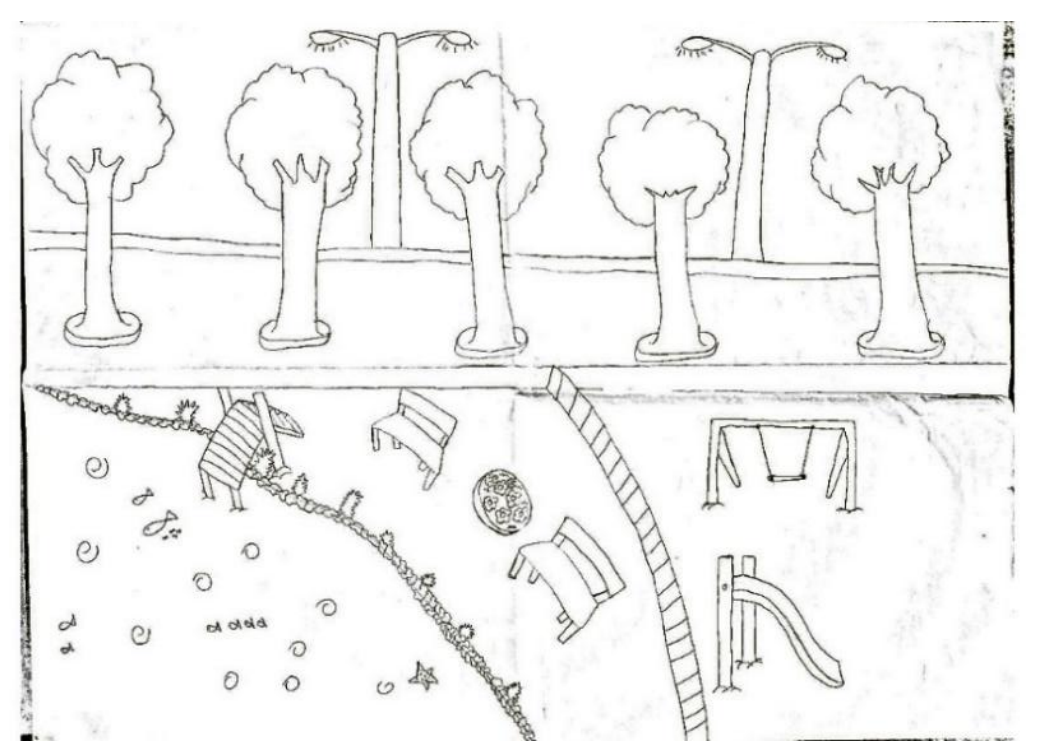

Source: The own author.

Figure 4 below shows the text created from an investigation on which public facilities would contribute to the improvement of the life of the city's inhabitants. The team points to the need to build cultural equipment that can promote culture and leisure for the population, express cultural practices, creativity, and other artistic expressions.

Figure 4: Intervention proposal for culture.

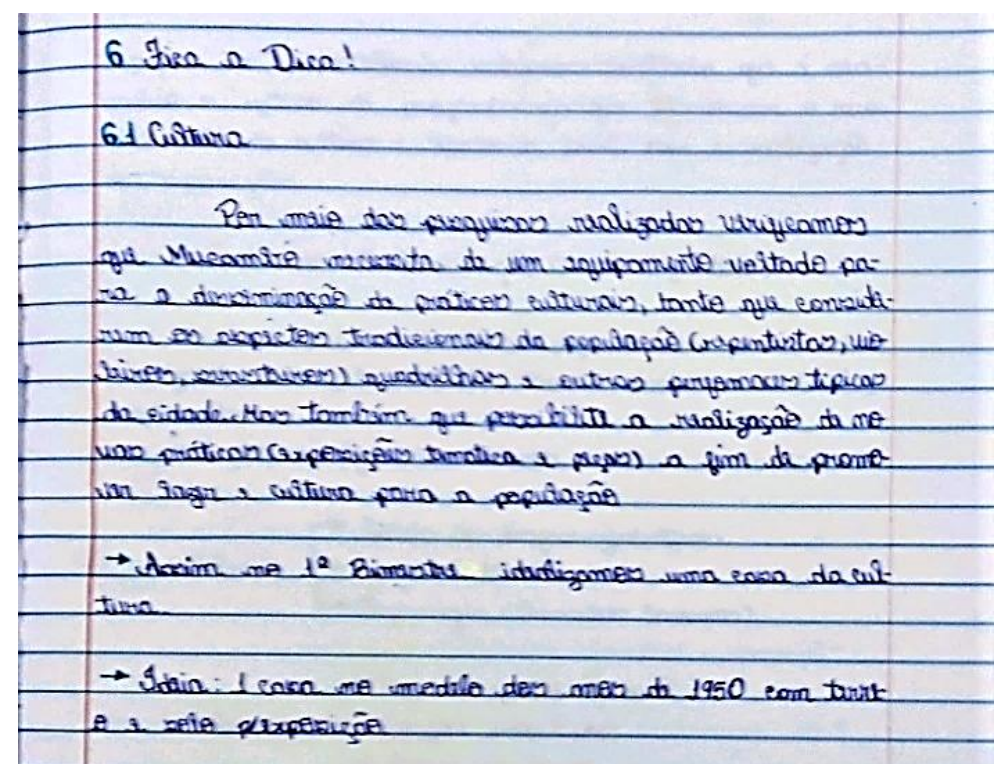

Source: The own authors. 
Another team, with a more historical conception, created a design with its perception about the most representative spaces of socioeconomic and cultural flows for the population.

Figure 5: Drawing of notorious public buildingsin Mucambo-CE.

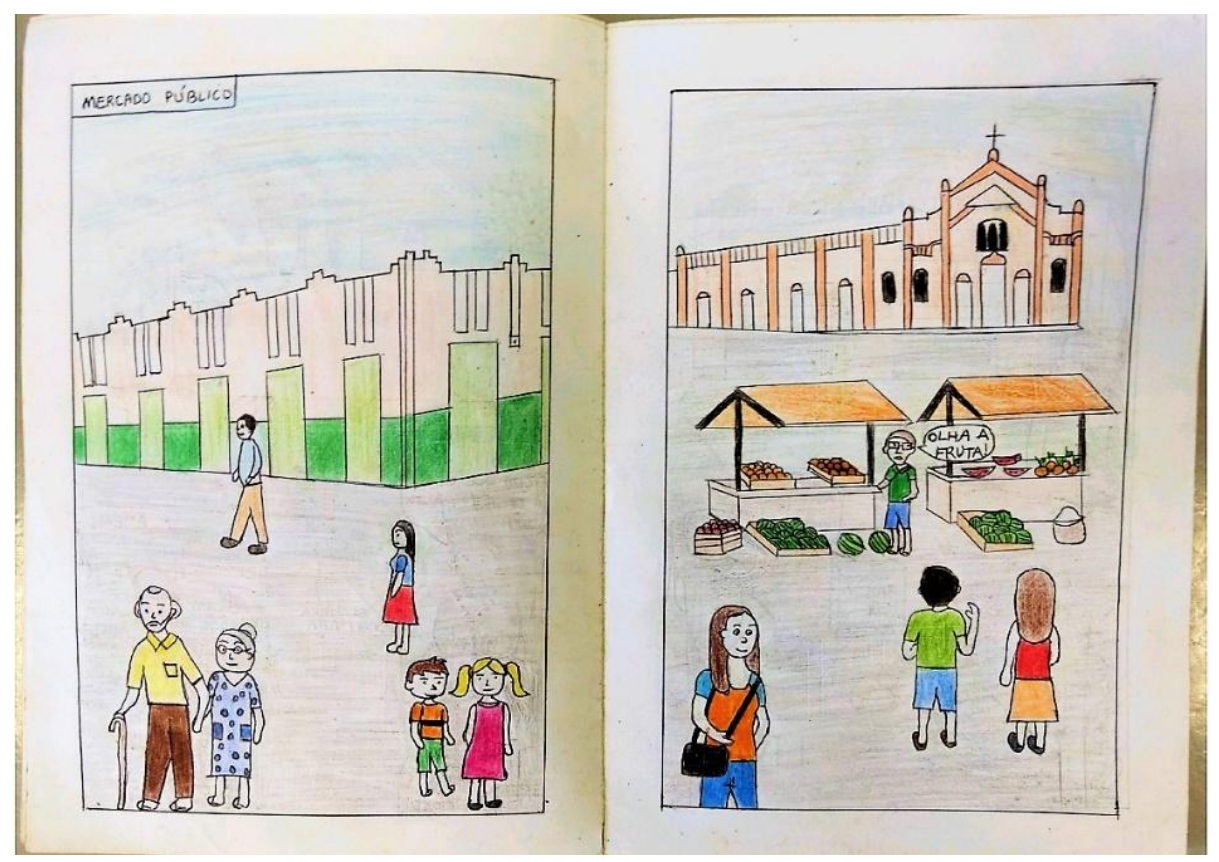

Source: The own authors.

Regarding the videos, they were complementary resources for discussions based on the textbook. They were available during classes for the teams to reassemble later, relating to their experiences in Mucambo-CE.

Students had to think about the type of video - whether it was a documentary or fiction -the information, the purpose perceived in terms of emotion generated, and the relationship with geography.

Teachers uploaded the videos on YouTube according to chapter and topicin the textbook so that other teams, assisted by other teachers, were responsible for researching and choosing the video for each class. The class that discussed the theme of urbanization and city watched the movie The City, from the Canadian series Ecce Homo, and directed by Pierre Lawrence (https://www.youtube.com/watch?v=iVrZtaQp0r4mais).

Thinking about the issue of Brazil's territorial occupation, students watched a series of videos produced within the scope of Rizoma Estúdio's Enraizando Project. They watched, respectively, the series The Indigenous - Roots of Brazil \#1 (https://www.youtube.com/watch?v=cQkA5PDow2s), The Portuguese - Roots of Brazil \#2 (https://www.youtube.com/watch? v=HfaeWT6qZ10), The Africans - Roots of Brazil \#3 (https://www.youtube.com/watch?v=fGUFwFYx46s).

About the problems in the field, students watched Silvio Tendler's film The Poison is on Table II, produced in 2014 (https://www.youtube.com/watch?v=fyvoKljtvG4). Regarding hunger, they watched adocumentarycalled The Road to Hunger from the Reporter Record Investigation Program. On industrialization, the video was from aVeccon channel on YouTube, with the title Brazilian Industrialization (https://www.youtube.com/watch?v=zFY5yaaWRXw).

In the sequence, each team had to produce its video, relating the topics seen with the context of its city. From the available resources (cell phones and technical capacity of assembly and editing through applications), the teams created videos that were posted on social networks,such as the video Project Rethinking the City (https://www.youtube.com/watch?v=d-bQY3-SI1Q).

\section{Final Considerations}

Given the reports outlined in this work, it is noticeable the importance of breaking some traditional methodological options in the field of education. One of them refers to the idealization of a passive student who receives the contents from the teachers, meaning, for this conception, learning. The contents are instruments of reflection for a contextualized way, involving the participation of the student in the process of producing learning. They are coresponsible for education. 
The evaluation made is that the pedagogical intervention caused an awakening for the student's protagonism in the production of knowledge. There are ways of treating the contents in a way to reflect on the intention of textbooks to stimulate perceptions and production of new contextualized contents. The dismantling is a form to overcome some visions regarding school books, such as that which places its contents as incontestable, true, absolute, not being subject to revision. The knowledge produced in this project undergoes dismantling and reassembling, according to the student's interest and understanding.

In this perspective, the dismantling of textbook contents provided by the school in the Geography classes can contribute so that the student can not only assimilate but transpose and transform these contents, being useful to think and act in the place where they live. Besides, learning and teaching Geography require possibilities to connect the didactic materials with the reality of the students. In this way, the actions carried out based on this project have awakened the critical-reflexive participation of students through the analysis of information in their resources.

In the same way, the dismantling methodology used in the Geography classes provides the school context with the promotion of the development of the analytical, critical, and creative capacity of the students, considering the intentionality of the information dealt with in books and external videos. It also helps students to formulate their own opinion regarding their space, which is significant in the current social and socioeconomic context.

The posture about the contents and the action of dismantling can promote the development of the analytical, critical, and creative capacity of the students, considering the information treated in the didactic resources with their space of perception, with their city, making them establish relations between the data in the books and their reality.

The proposal has helped students to formulate their opinions concerning the city where they live, which is relevant for the current social and socioeconomic context. Thus, it is necessary to know about the dynamics.

Finally, the most significant contribution of this proposal in the teaching of Geography is the possibility of offering means of reflection from the photographs and videos brought by the books used in class, consistent with the curricular proposals, identifying the intentionalities and contributing to the production of materials and new contents for the geographic topics.

\section{References}

AZEVEDO, Aina. Drawing and Anthropology. Historical recovering and thecurrent moment. Anthropology Notebooks. [online]. v. 5, n. 2, p.15-32, 2016. Available at https://journals.openedition.org/cadernosaa/1096. AccessedinJanuary 2020.

BRAZIL. MINISTRY OF EDUCATION. Common National Base Curriculum. Electronic Document. Available athttp://basenacionalcomum.mec.gov.br/images/BNCC_EI_EF_110518_versaofinal_site.pdf. AccessedinSeptember 2019.

CORRÊA, Roberto L. Urban Space. São Paulo: Ática, 1989.

FLUSSER, Vilém. Black Box Philosophy:trials for a future photograph philosophy. São Paulo: HUCITEC, 1985. Available athttp://www.iphi.org.br/sites/filosofia_brasil/Vil\%C3\%A9m_Flusser__Filosofia_da_Caixa_Preta.pdf. Accessed in January 2020.

GAMA. Fabiane. Building portfoliosfor collection: notes on representativity, slums,and visuality. In: PEIXOTO, Clarice E. Anthropology, and images. Rio de Janeiro: Garamond, 2001.

HIRATA, Helena. Gender, class e race. Intersectionalityand consubstantialityof social relationships. Soc. Time [online]. v. 26, n.1, p.61-73, 2014.

LE GOFF. Jacques. Historyand Memory/Document/Monument. São Paulo: Campinas State University, Campinas, 1990.

SANTOS, José E. Disorder,and regress: thenewhigh school modelingand thecivic disability withoutknowingto think ofspaceand acting on it. GeographyTeaching and Research, Santa Maria, vol. 23, n. 4, p. 1-48, June 2019. Available at<https://periodicos.ufsm.br/geografia/article/ view/30993>. AccessedonFebruary $1^{\text {st }}, 2020$. 